\title{
Olive Oil Consumption, BMI, and Risk of Obesity in Spanish Adults
}

\author{
Alejandra D. Benítez-Arciniegaa, b David Gómez-Ulloac Anna Vilac \\ Laia Giralt $^{d}$ Daniel Colprim ${ }^{e} \quad$ Maria-Asunción Rovira Martori ${ }^{a}$ \\ Helmut Schröder ${ }^{a, b}$ \\ ${ }^{a}$ Cardiovascular Risk and Nutrition Research Group (CARIN-ULEC), Research Program in \\ Inflammatory and Cardiovascular Disorders (RICAD), IMIM (Institut de Recerca Hospital \\ del Mar) Barcelona, Biomedical Research Park (Parc de Recerca Biomèdica de Barcelona - \\ PRBB), Barcelona, ${ }^{b}$ Network of Centers for Biomedical Research (Centros de Investigación \\ Biomédica en Red - CIBER), Physiopathology of Obesity and Nutrition (CIBEROBN), \\ Instituto de Salud Carlos III, Madrid, ' Department of Pharmacy, d Department of \\ Pulmonology, Hospital del Mar, ${ }^{e}$ Institute of Geriatrics (IGER). Centro Forum, Parc de \\ Salut Mar, Barcelona, Spain
}

\section{Key Words}

Olive oil $\cdot$ Obesity $\cdot$ BMI $\cdot$ Energy underreporting

\begin{abstract}
Background: Olive oil is an energy-dense food frequently consumed in south European countries with increasingly high obesity prevalence. Evidence of the impact of olive oil consumption on BMI and the risk of obesity is limited. We analyzed this association taking into consideration the problem of energy underreporting. Methods: Cross-sectional data on 6,352 Spanish adults were analyzed. Dietary intake was assessed using a validated food frequency questionnaire. Height and weight were measured. Results: Higher olive oil consumption was not associated with energy compensation in the overall diet. Olive oil consumption was positively associated $(p<0.004)$ with BMI in non-energy-adjusted multivariate linear regression models. Statistical significance of this association disappeared after controlling for energy intake in plausible energy intake reporters. The obesity risk increased for olive oil consumption of more than 2 tablespoons/day in both plausible energy intake reporters (odds ratio 1.30 (95\% CI 1.01-1.70)) and energy intake underreporters (odds ratio 3.06 (95\% CI 2.15-4.35)). This association was not significant after additional adjustment for energy intake (odds ratio 1.19 (95\% CI 0.91-1.56)) in plausible energy intake reporters. Conclusion: Olive oil intake did not affect BMI and the risk of obesity after adjustment for total energy intake in plausible energy intake reporters. The lack of energy intake compensation for olive oil consumption might explain the positive associations in models not adjusted for energy.
\end{abstract}

Copyright (C) 2012 S. Karger GmbH, Freiburg 


\section{Introduction}

Olive oil is one of the most characteristic components and the main fat source of the traditional Mediterranean diet [1]. The health benefits of this dietary pattern are partially attributed to the consumption of olive oil $[2,3]$. On the other hand, a high consumption of an energy-dense food such as olive oil might favor weight gain in the long run. This is of particular interest because the main olive oil-consuming countries are among those with the highest obesity prevalence in Europe [4]. However, high olive oil consumption within the context of the Mediterranean diet pattern is not associated with an increased risk of obesity [5-7]. Furthermore, Bes-Rastrollo and colleagues [8] reported a null association between olive oil consumption and weight gain during 28.5 months of follow-up in university graduates.

Food consumption patterns have been changing over the past 40 years in Spain, with decreased adherence to the traditional Mediterranean diet during the last two decades [9]. However, olive oil availability did not change during this time frame [10]. Olive oil consumption without energy compensation within the total diet may increase the risk of energy overconsumption and consequently lead to weight gain. It has been suggested that a diet rich in olive oil, even in the Mediterranean context, might be responsible for the increasing obesity prevalence rates in south European countries [11, 12]. However, the relevant data is limited $[8,13,14]$.

This cross-sectional analysis examines the association of olive oil consumption with BMI and obesity risk in a representative Mediterranean population. We also determined the effect of energy adjustment and energy underreporting on these associations.

\section{Participants and Methods}

\section{Subjects}

Data were obtained from a population-based cross-sectional survey conducted in Girona (Spain) in 2005. This survey of randomly selected men and women included 6,352 men and women aged 35-80 years in 2005 (71.5\% response rate). After excluding subjects with extremely low reported energy intake $(<800$ kcal), extremely high values for BMI $\left(>60 \mathrm{~kg} / \mathrm{m}^{2}\right)$, or reported energy consumption corresponding to a physical activity level (PAL) $>2.4$, which exceeds the established upper limit for strenuous work or highly active leisure behaviors [15], the analysis included 2,817 men and 2,768 women. The project was approved by the local Ethics Committee (CEIC - IMAS, Barcelona, Spain).

\section{Dietary Assessment}

Food consumption was determined using a validated $[16,17]$ food frequency questionnaire (FFQ) administered by a trained interviewer. In a 166-item food list including alcoholic and non-alcoholic beverages, participants indicated their usual consumption and chose from 10 frequency categories ranging from never or less than once per month to 6 or more times per day. The FFQ included three items of olive oil consumption: refined olive oil, olive oil, and virgin olive oil. For the purpose of the study we calculated total olive oil consumption and categorized it in three categories: less than one tablespoon (0 to $\leq 13.49 \mathrm{~g}$ ), one to two tablespoons ( $\geq 13.50$ to $\leq 27.0 \mathrm{~g}$ ), and more than two tablespoons $(>27.0 \mathrm{~g})$.

Basal metabolic rate (BMR) was calculated using the predictive equations based on sex, age and body weight [18]. Consistent with recommended cut-offs in the literature [19], the cut-off used to identify energy intake underreporters was energy intakes/BMR $<1.20$. Subjects with energy intake to BMR ratios $\geq 1.20$ were classified as plausible reporters.

\section{Anthropometric Measurements}

A calibrated precision scale was used for weight measurement. Readings were rounded up to $200 \mathrm{~g}$. Height was measured in the standing position and rounded up to $0.5 \mathrm{~cm}$. BMI was determined as weight divided by height squared $\left(\mathrm{kg} / \mathrm{m}^{2}\right)$. 
Other Variables

Leisure-time physical activity (LTPA) was measured by the validated Minnesota LTPA questionnaire administered by a trained interviewer [20,21]. Measurements of smoking habits and demographic and socioeconomic variables were obtained through structured standard questionnaires administered by trained personnel. Participants were categorized as non-smokers, former smokers (less than 1 year of smoking cessation), and current smokers. Maximum education level attained was elicited and recorded for analysis as primary school and secondary school or university.

\section{Statistical Analysis}

Characteristics of the participants were assessed by comparing means or proportions across the three categories of olive oil consumption. Analysis of variance was used to estimate the association between olive oil consumption category and age, physical activity, alcohol consumption, cigarette smoking, level of education, BMI, or energy underreporting. The significance of sex-adjusted linear trends across olive oil consumption categories was assessed by including these categories as ordinal variables in linear (for continuous variables) or logistic (for categorical variables) regression models adjusted for sex.

Linear regression models were fitted to determine the association between olive oil consumption and BMI. Dummy variables (olive oil consumption categories) were used in these models. We first analyzed the sex- and age-adjusted association, followed by additional adjustment for LTPA, smoking, educational level, and alcohol consumption. Finally, we examined the effect of energy adjustment on the relationship between BMI and olive oil consumption. Interactions between categories of olive oil consumption and i) energy underreporting (yes/no) and ii) sex were examined, with BMI as the outcome variable. As a significant $(\mathrm{p}<0.001)$ interaction was found with models for underreporting, olive oil consumption was stratified by underreporting status. No significant interaction with sex ( $p=0.748)$ was found.

Logistic regression models were used to analyze the relationship between olive oil consumption and obesity risk. We applied the same adjustment procedure as in linear regression models. Interaction with underreporting was also significant $(\mathrm{p}<0.001)$ in the logistic regression model. The Statistical Package for Social Science (SPSS) Version 13 (SPSS Inc., Chicago, IL, USA) was used for all statistical analyses. Association was considered significant if $\mathrm{p}<0.05$.

\section{Results}

Only $1.5 \%$ (men $1.8 \%$ and women $1.2 \%$ ) of the present population reported no olive oil consumption. Mean daily olive oil intake was $28.0 \pm 18.0 \mathrm{~g}(26.4 \pm 17.7 \mathrm{~g}$ in men and 29.6 $\pm 18.1 \mathrm{~g}$ in women).

The association of olive oil consumption with BMI, obesity, and lifestyle was quite similar for both sexes. Furthermore, there was no significant interaction between sex and olive oil consumption. For these reasons we present nonstratified results, adjusted by sex when appropriate.

Higher olive oil consumption was observed among women (table 1). People consuming higher amounts of olive oil were older, had a lower educational level, less likely to underreport energy intake, and reported that they spend more time in LTPA, smoke less, and drink more alcohol compared to the lower olive oil consumption group (table 1).

Higher intakes of total energy, total fat, and monosaturated and polyunsaturated fatty acids were observed among people consuming higher amounts of olive oil, whereas the contrary was observed for carbohydrate and protein intakes (table 2). Intakes of meat, fish, pastry, and fruits, but not vegetable consumption, decreased across categories of olive oil consumption (table 2).

The age- and sex-adjusted positive relationship between olive oil consumption and BMI was attenuated but remained significant after additionally controlling for LTPA, smoking, educational level, and alcohol consumption (table 3). Statistical significance of this association disappeared after entering the total energy intake of plausible energy intake reporters into this multiple linear regression model (table 3). 
Table 1. Sex-adjusted characteristics of study participants according to categories of olive oil consumption*

\begin{tabular}{|c|c|c|c|c|}
\hline & \multicolumn{3}{|c|}{ Olive oil consumption, TBSP/day } & \multirow[t]{2}{*}{$\mathrm{p}$ value } \\
\hline & $\begin{array}{l}\leq 1 \\
(n=749)\end{array}$ & $\begin{array}{l}>1 \text { and } \leq 2 \\
(n=2,205)\end{array}$ & $\begin{array}{l}>2 \\
(n=2,631)\end{array}$ & \\
\hline Men, \% & $62.1(58.5-65.6)$ & $52.0(49.9-54.0)$ & $45.8(43.9-47.7)$ & $<0.001$ \\
\hline Age, years & $54.8(53.9-55,7)$ & $55.7(55.1-56.2)$ & $58.4(57.9-58.9)$ & $<0.001$ \\
\hline Current smokers, \% & $24.3(21.4-27.3)$ & $23.0(21.3-24.7)$ & $20.4(18.9-22.0)$ & 0.008 \\
\hline LTPA, METs*min/day & $286.6(263.4-309.9)$ & $304.7(291.2-318.2)$ & $326.5(314.1-338.8)$ & 0.003 \\
\hline More than primary education, $\%$ & $53.4(49.8-57.01)$ & $53.9(51.8-56.0)$ & $46.9(45.0-48.9)$ & 0.002 \\
\hline Alcohol consumption, g/day & $7.7(6.8-8.6)$ & $9.0(8.5-9.5)$ & $9.4(8.9-9.8)$ & 0.002 \\
\hline Low energy reporters, $\%^{\mathrm{a}}$ & $40.7(37.9-43.5)$ & $25.4(23.8-27.0)$ & $11.7(10.2-13.2)$ & $<0.001$ \\
\hline $\mathrm{BMI}, \mathrm{kg} / \mathrm{m}^{2}$ & $27.0(26.7-27.4)$ & $27.3(27.2-27.5)$ & $27.9(27.8-28.1)$ & $<0.001$ \\
\hline
\end{tabular}

TBSP = Tablespoon; LTPA = leisure time physical activity; METs = metabolic equivalents.

*Values are means or percentages (95\% CI in parentheses).

aEnergy intake: basal metabolic ratio $<1.2$.

Table 2. Sex- and age-adjusted intakes of energy, nutrients and food groups according to categories of olive oil consumption

\begin{tabular}{|c|c|c|c|c|}
\hline & \multicolumn{3}{|c|}{ Olive oil consumption, TBSP/day } & \multirow[t]{2}{*}{$\mathrm{p}$ value } \\
\hline & $\begin{array}{l}\leq 1 \\
(n=749)\end{array}$ & $\begin{array}{l}>1 \text { and } \leq 2 \\
(n=2,205)\end{array}$ & $\begin{array}{l}>2 \\
(n=, 2,631)\end{array}$ & \\
\hline Energy value, kcal/day* & $52.2(45.1-59.2)$ & 161.9 (157.8-165.9) & $385.2(381.4-388.9)$ & $<0.001$ \\
\hline Total energy, kcal/daya & $2,019(1,978-2,060)$ & $2,262(2,238-2,286)$ & $2,540(2,518-2,561)$ & $<0.001$ \\
\hline Carbohydrates, E\% & $43.9(43.4-44.4)$ & $42.7(42.4-43.0)$ & $39.2(38.9-39.5)$ & $<0.001$ \\
\hline Protein, E\% & $19.1(18.9-19.3)$ & $18.3(28.2-18.4)$ & $16.6(16.5-16.7)$ & $<0.001$ \\
\hline Total fat, E\% & $37.2(36.8-37.6)$ & $39.2(39.0-39.5)$ & $44.3(44.1-44.6)$ & $<0.001$ \\
\hline Saturated fat, E\% & $12.5(12.3-12.6)$ & $12.0(11.9-12.1)$ & $11.9(11.8-12.0)$ & 0.936 \\
\hline Monosaturated fat, E\% & $16.4(16.2-16.7)$ & $18.8(18.6-18.9)$ & $23.4(23.3-23.5)$ & $<0.001$ \\
\hline Polyunsaturated fat, E\% & $5.8(5.7-5.9)$ & $5.9(5.8-6.0)$ & $6.3(6.2-6.4)$ & $<0.001$ \\
\hline Vegetables, g/1,000 kcal & $160.3(152.2-168.4)$ & $180.6(176.0-185.4)$ & 183.3 (179.0-187.7) & $<0.001$ \\
\hline Fruits, g/1,000kcal & $195.4(186.2-204.5)$ & 194.0 (188.7-199.4) & $178.0(173.2-183.0)$ & $<0.001$ \\
\hline Meat, g/1,000 kcal & $53.1(51.5-54.7)$ & $47.6(46.6-48.5)$ & $42.8(41.9-43.6)$ & $<0.001$ \\
\hline Fish, g/1,000 kcal & $35.0(33.6-36.4)$ & $35.3(34.5-36.1)$ & $33.0(32.2-33.7)$ & 0.014 \\
\hline Pastry, g/1,000 kcal & $13.3(12.4-14.1)$ & $11.6(10.6-12.0)$ & $9.5(9.1-10.0)$ & $<0.001$ \\
\hline
\end{tabular}

TBSP = Tablespoon .

*Energy intake from olive oil.

aTotal energy intake.

$\mathrm{b} \%$, percentage of total energy intake.

Logistic regression analysis revealed that the relationship between obesity risk and olive oil consumption was comparable to that between BMI and olive oil intake in linear regression models (table 4). The significant risk of obesity among people consuming higher amounts of olive oil and showing plausible energy intakes observed in multiple adjusted models was attenuated after controlling for total energy intake (table 4). 
Table 3. Multivariate-adjusted association between body mass index and olive oil consumption among plausible energy reporters and low energy reporters

\begin{tabular}{|c|c|c|c|c|c|c|c|c|}
\hline & \multicolumn{4}{|c|}{ Plausible energy reporters* } & \multicolumn{4}{|c|}{ Energy underreporters* } \\
\hline & $\mathrm{n}$ & coefficient & $95 \% \mathrm{CI}$ & $\mathrm{p}$ value & $\mathrm{n}$ & coefficient & $95 \%$ CI & $\mathrm{p}$ value \\
\hline \multicolumn{9}{|l|}{ Model 1a } \\
\hline$<1$ TBSP & 434 & reference & & & 315 & reference & & \\
\hline$\geq 1$ and $\leq 2$ TBSP & 1,641 & 0.167 & -0.276 to 0.613 & 0.463 & 564 & 1.109 & $0.465-1.752$ & 0.001 \\
\hline$>2$ TBSP & 2,338 & 0.703 & $0.269-1.137$ & 0.002 & 293 & 3.125 & $2.377-3.874$ & $<0.001$ \\
\hline \multicolumn{9}{|l|}{ Model 2b } \\
\hline$<1$ TBSP & 434 & reference & & & 315 & reference & & \\
\hline$\geq 1$ and $\leq 2$ TBSP & 1,641 & 0.165 & -0.289 to 0.596 & 0.495 & 564 & 1.186 & $0.544-1.828$ & $<0.001$ \\
\hline$>2$ TBSP & 2,338 & 0.658 & $0.226-1.089$ & 0.003 & 293 & 3.042 & $2.294-3.790$ & $<0.001$ \\
\hline \multicolumn{9}{|l|}{ Model 3c } \\
\hline$<1$ TBSP & 434 & reference & & & 315 & reference & & \\
\hline$\geq 1$ and $\leq 2$ TBSP & 1,641 & 0.051 & -0.386 to 0.488 & 0.820 & 564 & 0.480 & $\begin{array}{l}-0.151 \text { to } \\
1.111\end{array}$ & 0.136 \\
\hline$>2$ TBSP & 2,338 & 0.310 & -0.119 to 0.740 & 0.157 & 293 & 1.969 & $1.221-2.717$ & $<0.001$ \\
\hline $\begin{array}{r}\text { TBSP = Tabl } \\
\text { *Plausible re } \\
\text { er defined as en } \\
\text { aModel } 1 \text { adj } \\
\text { bModel } 2 \text { adj } \\
\text { school and seco } \\
\text { ers), and alcoho } \\
\text { cModel } 3 \text { ad } \\
\text { school or unive } \\
\text { tion (g/day), an }\end{array}$ & $\begin{array}{l}\text { espoon } \\
\text { eportin } \\
\text { lergy in } \\
\text { justed } \mathrm{f} \\
\text { justed } \mathrm{f} \\
\text { ondary } \\
\text { l consu } \\
\text { djusted } \\
\text { rsity), } \\
\text { d ener }\end{array}$ & $\begin{array}{l}\text { n. } \\
\text { ntake defined as } \\
\text { for sex and a } \\
\text { for sex, age } \\
\text { school or ur } \\
\text { umption (g/ } \\
\text { for sex, ag } \\
\text { smoking (no } \\
\text { gy intake (k }\end{array}$ & $\begin{array}{l}\text { s energy intake to } \\
\text { al metabolic rate } \\
\text { age (years). } \\
\text { (years), physical } \\
\text { iniversity), smokir } \\
\text { day). } \\
\text { e, physical activit } \\
\text { on-smokers, form } \\
\text { cal). }\end{array}$ & $\begin{array}{l}\text { basal met } \\
\text { atio }<1.2 \text {. } \\
\text { ctivity (M } \\
\text { g (non-sn } \\
\text { y, educat } \\
\text { er smoke }\end{array}$ & $\begin{array}{l}\text { Ts } \times \mathrm{n} \\
\text { okers, } \\
\text { nal le } \\
\text {, and }\end{array}$ & $\begin{array}{l}\text { min/day), e } \\
\text { former sm } \\
\text { evel (prima } \\
\text { current sm }\end{array}$ & $\begin{array}{l}\text { ducational lev } \\
\text { okers, and cur } \\
\text { ry school and } \\
\text { okers), alcoho }\end{array}$ & $\begin{array}{l}\text { derreport- } \\
\text { (primary } \\
\text { rent smok- } \\
\text { secondary } \\
\text { consump. }\end{array}$ \\
\hline
\end{tabular}

\section{Discussion}

Olive oil consumption was positively associated with BMI and obesity risk in plausible and implausible energy intake reporters. However, the magnitude of these associations was stronger in subjects with implausible energy intakes. Controlling for total energy intake shifted these associations toward zero only in subjects reporting plausible energy intakes.

The obesity epidemic greatly affects south European countries [11, 12]. A positive energy balance is the driving force of this epidemic. High consumption of energy-dense foods such as vegetable oils, if not compensated by the intake of less energy-dense foods, is likely to disturb energy balance.

Olive oil is the main added fat source in south European countries. Mean olive oil consumption in the present population is comparable to that reported for other Mediterranean populations [4]. Furthermore, it contributes $10.7 \%$ to total energy intake, making olive oil the most important single food in the energy balance. As reported for dietary components with little effect on satiety such as alcohol [22], there was no reduction in the intake of other sources of energy to compensate for the energy intake from olive oil. The additional mean $333 \mathrm{kcal}$ from olive oil among people consuming higher amounts of olive oil is likely to increase the risk of energy overconsumption and consequently of weight gain. Energy underreporting biases measures of energy intake, which is particularly problematic 
Table 4. Odds ratios of obesity according to olive oil consumption category among plausible energy reporters and low energy reporters

\begin{tabular}{|c|c|c|c|c|c|c|}
\hline & \multirow[b]{2}{*}{$\mathrm{n}$} & \multicolumn{2}{|c|}{ Plausible energy reporters* } & \multicolumn{3}{|c|}{ Energy underreporters* } \\
\hline & & odds ratio & $95 \% \mathrm{CI}$ & $\mathrm{n}$ & odds ratio & $95 \% \mathrm{CI}$ \\
\hline \multicolumn{7}{|l|}{ Model 1a } \\
\hline$<1$ TBSP & 434 & 1 (reference) & & 315 & 1 (reference) & \\
\hline$\geq 1$ and $\leq 2$ TBSP & 1,641 & 1.03 & $7.87-1.35$ & 564 & 1.57 & $1.16-2.14$ \\
\hline$>2$ TBSP & 2338 & 1.41 & $1.09-1.83$ & 293 & 3.26 & $2.31-4.59$ \\
\hline \multicolumn{7}{|l|}{ Model 2b } \\
\hline$<1$ TBSP & 434 & 1 (reference) & & 315 & 1 (reference) & \\
\hline$\geq 1$ and $\leq 2$ TBSP & 1,641 & 0.98 & $0.74-1.29$ & 564 & 1.59 & $1.16-2.18$ \\
\hline$>2$ TBSP & 2,338 & 1.30 & $1.01-1.70$ & 293 & 3.06 & $2.15-4.35$ \\
\hline \multicolumn{7}{|l|}{ Model 1 ${ }^{\mathrm{c}}$} \\
\hline$<1$ TBSP & 434 & 1 (reference) & & 315 & 1 (reference) & \\
\hline$\geq 1$ and $\leq 2$ TBSP & 1,641 & 0.95 & $0.72-1.25$ & 564 & 1.34 & $0.97-1.85$ \\
\hline$>2$ TBSP & 2,338 & 1.19 & $0.91-1.56$ & 293 & 2.45 & $1.70-3.51$ \\
\hline $\begin{array}{r}\text { TBSP = Tables } \\
\text { *Plausible rep } \\
\text { er defined as ene } \\
\text { aModel } 1 \text { adju } \\
\text { bModel } 2 \text { adju } \\
\text { school and secon } \\
\text { ers), and alcohol }\end{array}$ & $\begin{array}{l}\text { oon. } \\
\text { rting de } \\
\text { gy intake } \\
\text { ed for se } \\
\text { ted for s } \\
\text { ary scho } \\
\text { onsumpt }\end{array}$ & $\begin{array}{l}\text { ined as energy } \\
\text { to basal metab } \\
x \text { and age (year } \\
\text { ex, age (years), } \\
\text { ol or university } \\
\text { ion (g/day). }\end{array}$ & $\begin{array}{l}\text { ake to basal } \\
\text { rate ratio < } \\
\text { sical activity } \\
\text { moking (nol }\end{array}$ & $\begin{array}{l}\text { METs } \\
\text { moke }\end{array}$ & $\begin{array}{l}\text { ate ratio } \geq 1.2 \text {; } \\
\text { in/day), educa } \\
\text { former smoker }\end{array}$ & $\begin{array}{l}\text { rgy underreport- } \\
\text { hal level (primary } \\
\text { nd current smok- }\end{array}$ \\
\hline
\end{tabular}

for the analysis of the relationship between diet and weight [23]. The present study found a positive association of olive oil consumption with BMI and additionally with higher odds of obesity risk in models not adjusted for energy. These associations were notably weaker among plausible energy intake reporters. Of note, olive oil consumption up to two tablespoons (27 g) was not associated with a higher BMI or increased obesity risk compared to low olive oil intake (less than 1 tablespoon) among subjects with plausible energy intakes. The initially positive association between BMI, obesity risk, and olive oil consumption became zero after adjustment for energy intake in plausible energy intake reporters. Other studies have reported similar findings. Serra-Majem and collaborators [13] found no significant differences between BMI and quartiles of energy-adjusted olive oil consumption. Furthermore, no significant increase in weight or risk of obesity was found in university graduates reporting high olive oil consumption [8].

It has been shown that energy intake underreporters tend to report lower intakes of fat and energy-dense foods than plausible energy intake reporters [24]. For this reason it is reasonable to assume that the true amount of olive oil consumed by energy intake underreporters exceeds significantly the reported amount. This fact would explain the greater magnitude of olive oil consumption and of BMI and obesity in energy.

Although high-consuming subjects in the present study spend more time in LTPA than their low-consuming peers; controlling for LTPA did not attenuate the association between BMI and olive oil consumption. The absolute difference in LTPA between people consuming low and those consuming high amounts of olive oil , although significant, might be too small to exert a meaningful effect. 
A null or negative association between BMI and olive oil consumption in the context of the Mediterranean diet has been reported in cross-sectional and prospective epidemiological studies [5-7]. Indeed there are several mechanisms linking the Mediterranean diet with weight maintenance [25]. In the context of the Mediterranean diet one would expect that high consumption of olive oil is associated with a reduced consumption of other energydense foods such as meat and sausages. Unfortunately, food patterns have changed in recent decades, and consumption of high amounts of olive oil is not necessarily linked to the current diet of Mediterranean populations. In the present study only $58.7 \%$ of participants in the top tertile of olive oil consumption also showed high adherence to the rest of the Mediterranean diet (top tertile of the Mediterranean diet score not including olive oil; data not shown). Additionally, mixed results were found for the association of olive oil consumption and that of single food groups, a fact supported by previously published data $[13,14]$.

A limitation of the present study is its cross-sectional design, which precludes drawing causal relationships. A further limitation is the fact that $30 \%$ of the randomly selected subjects preferred not to participate. Hence, a self-selection bias cannot be ruled out. Furthermore, all dietary instruments such as food frequency questionnaires measuring past food intake are vulnerable both to random and systematic measurement errors. Finally, misreporting is an acknowledged source of measurement error in prospective or retrospective methods of dietary assessment using self-reported food intake records.

Nonetheless, this study has several important strengths, including a large populationbased sample with measured anthropometry and its consideration of the possible effects of energy intake underreporting.

This study shows that BMI and the risk of obesity increased with olive oil consumption when not controlled for total energy intake. Failure of energy compensation for olive oil consumption might explain this finding. However, at the isocaloriclevel, olive oil consumption did not affect BMI or obesity risk in plausible energy intake reporters. The latter finding underlines the importance of controlling for energy underreporting in studies of the relationships between nutrition and obesity.

\section{Authors' Contributions}

A.D. Benítez-Arciniega and D. Gómez-Ulloa contributed equally to the study, and each can be regarded as first authors of this article.

A.D. Benitez and D. Gomez-Ulloa prepared the manuscript and conducted the analysis, with significant input and feedback from all co-authors; A. Vila, L. Giralt, D. Colprim, M.A. Rovira Martori, and H. Schröder participated in the design and execution of the study and contributed to the critical revision of the manuscript for important intellectual content.

\section{Acknowledgements}

We appreciate the English revision made by Elaine Lilly, Ph.D. (Writers First Aid). The CIBEROBN is an initiative of the Instituto de Salud Carlos III, Madrid, (CB06/03/0028). This project was supported by research grants from the Centro de Investigación Biomédica en Red-Fisiopatología de la Obesidad y la Nutrición (CB06/03/0028); Instituto Carlos III (Red HERACLES RD06/0009), Fondo de Investigación Sanitaria. ISCIII/FEDER. (FIS PI080439) and by a joint contract of the Instituto de Salud Carlos III and the Health Department of the Catalan Government (Generalitat de Catalunya), CP 03/00115.

\section{Disclosure Statement}

None of the authors had potential conflicts of interest related to this manuscript, financial or otherwise. 


\section{References}

1 Keys A: Mediterranean diet and public health: personal reflections. Am J Clin Nutr 1995;61(suppl):1321S1323S.

- 2 Covas MI : Olive oil and the cardiovascular system. Pharmacol Res 2007;55:175-186.

- 3 Covas MI, Konstantinidou V, Fitó M: Olive oil and cardiovascular health. J Cardiovasc Pharmacol 2009;54: 477-482.

- 4 Linseisen J, Welch AA, Ocké M, Amiano P, Agnoli C, Ferrari P Sonestedt E, Chajès V, Bueno-de-Mesquita HB, Kaaks R, Weikert C, Dorronsoro M, Rodríguez L, Ermini I, Mattiello A, van der Schouw YT, Manjer J, Nilsson S, Jenab M, Lund E, Brustad M, Halkjaer J, Jakobsen MU, Khaw KT, Crowe F, Georgila C, Misirli G, Niravong M, Touvier M, Bingham S, Riboli E, Slimani N: Dietary fat intake in the European Prospective Investigation into Cancer and Nutrition: results from the 24-h dietary recalls. Eur J Clin Nutr 2009;63(suppl 4):S61-80. Schröder H, Marrugat J, Vila J, Covas MI, Elosua R: Adherence to the traditional Mediterranean diet is inversely associated with body mass index and obesity in a Spanish population. J Nutr 2004;134:3355-3361.

6 Trichopoulou A, Naska A, Orfanos P, Trichopoulos D: Mediterranean diet in relation to body mass index and waist-to-hip ratio: the Greek European Prospective Investigation into Cancer and Nutrition Study. Am J Clin Nutr 2005;82:935-940.

- 7 Mendez MA, Popkin BM, Jakszyn P, Berenguer A, Tormo MJ, Sanchéz MJ Quirós JR, Pera G, Navarro C, Martinez C, Larrañaga N, Dorronsoro M, Chirlaque MD, Barricarte A, Ardanaz E, Amiano P, Agudo A, González CA: Adherence to a Mediterranean diet is associated with reduced 3-year incidence of obesity. J Nutr 2006;136:2934-2938.

- 8 Bes-Rastrollo M, Sánchez-Villegas A, De la Fuente C, De Irala J, Martínez JA, Martínez-González MA: Olive oil consumption and weight change: the SUN Prospective Cohort Study. Lipids 2006;41:249-256.

9 Bach-Faig A, Fuentes-Bol C, Ramos D, Carrasco JL, Roman B, Bertomeu IF, Cristià E, Geleva D, Serra-Majem L: The Mediterranean diet in Spain: adherence trends during the past two decades using the Mediterranean Adequacy Index. Public Health Nutr 2011;14:622-628.

10 Vareiro D, Bach-Faig A, Raidó QB, Bertomeu I, Buckland G, Vaz de Almeida MD, Serra-Majem L: Availability of Mediterranean and non-Mediterranean foods during the last four decades: comparison of several geographical areas. Public Health Nutrition 2009;12:1667-1675.

11 Schröder H, Elosua R, Vila J, Marti H, Covas MI, Marrugat J: Secular trends of obesity and cardiovascular risk factors in a Mediterranean population. Obesity (Silver Spring) 2007;15:557-562.

12 Berghöfer A, Pischon T, Reinhold T, Apovian CM, Sharma AM, Willich SN: Obesity prevalence from a European perspective: a systematic review. BMC Public Health 2008;8:200-212.

13 Serra-Majem L, Ngo de la Cruz J, Ribas L, Tur JÁ: Olive oil and the Mediterranean diet: beyond the rhetoric. Eur J Clin Nutr 2003;57(suppl 1):S2-7.

$\checkmark 14$ Soriguer F, Almaraz MC, Ruiz-de-Adana MS, Esteva I, Linares F, García-Almeida JM, Morcillo S, GarcíaEscobar E, Olveira-Fuster G, Rojo-Martínez G: Incidence of obesity is lower in persons who consume olive oil. Eur J Clin Nutr 2009;63:1371-1374.

15 Black AE, Coward WA, Cole TJ, Prentice AM. Human energy expenditure in affluent societies: an analysis of 574 doubly-labelled water measurements. Eur J Clin Nutr 1996;50:72-92.

16 Schröder H, Covas MI, Marrugat J, Vila J, Pena A, Alcántara M, Masiá R: Use of a three-day estimated food record, a 72-hour recall and a food-frequency questionnaire for dietary assessment in a Mediterranean Spanish population. Clin Nutr 2001;20:429-437.

-17 Benítez-Arciniega AA, Mendez MA, Baena-Díez JM, Rovira Martori MA, Soler C, Marrugat J, Covas MI, Sanz H, Llopis A, Schröder H: Concurrent and construct validity of Mediterranean diet scores as assessed by an FFQ. Public Health Nutr 2011;14:2015-2021.

-18 Schofield WN: Predicting basal metabolic rate, new standards and review of previous work. Hum Nutr Clin Nutr 1985;39(suppl 1):5-41.

19 Huang TT, Roberts SB, Howarth NC, McCrory MA: Effect of screening out implausible energy intake reports on relationships between diet and BMI. Obes Res 2005;13:1205-1217.

20 Elosua R, Marrugat J, Molina L, Pons S, Pujol E: Validation of the Minnesota Leisure Time Physical Activity Questionnaire in Spanish men. The MARATHOM Investigators. Am J Epidemiol 1994;139:1197-1209.

21 Elosua R, García M, Aguilar A, Molina L, Covas MI, Marrugat J: Validation of the Minnesota Leisure Time Physical Activity Questionnaire in Spanish women. Investigators of the MARATHOM group. Med Sci Sports Exerc 2000;32:1431-1437.

22 Yeomans MR: Effects of alcohol on food and energy intake in human subjects: evidence for passive and active over-consumption of energy. Br J Nutr 2004;92(suppl 1):S31-S34.

23 Mendez MA, Covas MI, Marrugat J, Vila J, Schröder H: Glycemic load, glycemic index, and body mass index in Spanish adults. Am J Clin Nutr 2009;89:316-322.

24 Mendez MA, Popkin BM, Buckland G, Schroder H, Amiano P, Barricarte A, Huerta JM, Quirós JR, Sánchez MJ, González CA: Alternative methods of accounting for underreporting and overreporting when measuring dietary intake-obesity relations. Am J Epidemiol 2011;173:448-458.

-25 Schröder H: Protective mechanisms of the Mediterranean diet in obesity and type 2 diabetes. J Nutr Biochem 2007; 18:149-160. 